\title{
REVISION JURISPRUDENCIAL ACERCA DE LA RESPONSABILIDAD DE LAS EMPRESAS CONCESIONARIAS DE RUTAS FRENTE AL USUARIO
}

VERONICA MARIA LAURA GLIBOTA LANDRIEL FACULTAD DE CIENCIAS ECONÓMICAS - UNNE

"Se piensa que lo justo es lo igual, y así es; pero no para todos, sino para los iguales. Se piensa por el contrario que lo justo es lo desigual, y así es, pero no para todos, sino para los desiguales". 


\title{
RESUMEN
}

l presente artículo se enmarca en la perspectiva de una revisión de la concepción
jurisprudencial argentina acerca de la responsabilidad derivada de los accidentes
ocurridos en rutas concesionadas, desde la aplicación de principios propios del
Derecho Administrativo, hasta llegar al estado actual de situación, en el que la
Corte Suprema de Justicia instituye y caracteriza a la relación de las empresas concesiona-
rias y los usuarios como una relación de consumo, logrando traspasar la esfera del Derecho
Público hacia el ámbito del Derecho Privado patrimonial, y más aún, hacia el subsistema de
Derecho de Consumo, con las implicancias que tal determinación acarrea. En ese orden, se ha
pretendido ahondar en la temática de los daños al consumidor, vislumbrando -en los casos
de daños derivados de accidentes en rutas concesionadas, causados por animales sueltos-, un
verdadero cambio paradigmático en la interpretación de las soluciones propugnadas, a través
de la inclusión de la temática al ámbito de las relaciones de consumo, con la incorporación de
la noción del servicio defectuosoy, con él, la responsabilidad objetiva y solidaria del proveedor
del servicio, a la luz de la normativa tuitiva vigente.

Palabras clave: Consumo - responsabilidad - servicios defectuosos - concesionarias viales usuarios - accidentes.

\begin{abstract}
This article is part of the prospect of a design review of the Argentina case law on liability for accidents on roads under concession from the application of proper principles of administrative law, until the current situation, in which the Supreme Court establishes and characterizes the relationship of the concessionary companies and the users as a consumer relationship, making crossing the sphere of public law into the realm of private law patrimonial and further, to the subsystem of Law of Consumer, with the implications that this entails determination.

In that order, have sought to delve into the issue of damage to the consumer, seeing in cases of damage resulting from accidents on routes or concession roads caused by stray animals, a true paradigm shift in the interpretation of the solutions advocated, through the inclusion of the topic into the realm of consumer relations, with the addition of the notion of defective service, and with it the liability and supportive service provider, in light of the protective rules in force.
\end{abstract}

Keywords: Consumption - responsibility - defective services - concessionary road users - accidents. 


\section{INTRODUCCIÓN}

Señalar a la responsabilidad de las empresas concesionarias de peaje por accidentes causados por animales sueltos en ruta, como un supuesto de responsabilidad objetiva derivada de una relación de consumo, tal como lo ha hecho la Corte Suprema de Justicia de la Nación argentina (CSJN) en los últimos pronunciamientos sobre dicha cuestión, ha venido a producir un giro copernicano en lo que hasta ahora se había entendido como un conflicto resuelto por normas del Derecho Público, principalmente del Derecho Administrativo, que permitieron en una primera instancia exonerar a las empresas juntamente con el Estado, en su carácter de concedente del servicio.

Esto ha motivado el debate y una nueva confrontación que observamos con beneplácito, en aras de una mejor y mayor protección al usuario-consumidor, reconocido por el más Alto Cuerpo Judicial.

Podemos afirmar, sin temor a equivocarnos, que se ha operado en este sentido un verdadero cambio paradigmático en la determinación de los sujetos responsables y la ponderación de los factores de atribución de responsabilidad que sobre los mismos pesan, que obedece a la distinta consideración que se hace de la relación jurídica preexistente entre el usuario de las rutas y las concesionarias y, a la postre, el Estado concedente.

En efecto, consideramos la inclusión de esta cuestión por la trascendencia y la actualidad que tiene por estos días en la Argentina, la temática relativa a la prestación de servicios y la consecuencia derivada del servicio defectuosamente prestado, a partir de sendos fallos de la Corte Suprema de Justicia de la Nación, que han venido a modificar sustancialmente el criterio hasta ahora considerado de sentar la responsabilidad en el Estado concedente y en terceros, hacia la ponderación de la relación entre empresa concesionaria y usuario de la ruta como una relación de consumo con las implicancias que ello apareja.

Sostenemos por ende, que el presente trabajo se constituye en un análisis revisionista de un verdadero paradigma de la responsabilidad por daños, no sólo porque vira la determinación de la naturaleza de la relación usuario-concesionaria desde la visión del Derecho Público hacia el ámbito de las relaciones privadas, sino en particular, porque permite la caracterización de la misma como una relación de consumo, cuya responsabilidad queda fundada en una obligación de resultado de la que deriva el deber accesorio de seguridad, todo con expresa regulación en la norma de la Ley 24.240, de Defensa del Consumidor.

Por otra parte, porque amplía y reconoce el ámbito de protección de los consumidores hacia los usuarios de servicios públicos tercerizados y concesionados, constituyéndose en un valioso precedente.

Básicamente, y a través del estudio de distintos fallos pronunciados en diversas instancias -particularmente de la CSJN-, lo que pretendemos lograr es establecer el modo en que se fue caracterizando a la responsabilidad de estas empresas y los diversos criterios que a lo largo del tiempo fueron considerados por los Jueces para imputarles la indemnización por daños, o exonerarlas de responsabilidad por los accidentes ocurridos debido a la existencia de 
animales sueltos, en las rutas que le fueran concesionadas por el Estado. Particularmente, la incorporación de estos supuestos de daños causados por defecto en la prestación de un servicio público como inherentes al Derecho del Consumidor, y la aplicación de la normativa afín y los principios protectorios.

A partir de la instauración de la política económica neoliberal de descentralización y privatización de los servicios públicos -incluyendo la concesión de las rutas nacionales que quedaron en manos de empresas privadas-, se ha controvertido en el ámbito del Derecho acerca de si la empresa concesionaria es la que debe responder frente a la víctima de un accidente de tránsito ocasionado por un animal suelto, de manera conjunta con el propietario o guardián del mismo (art. 1.124 Código Civil'), o si quien debe responder es el propio Estado (concedente) por incumplimiento de su deber de policía; quedando por lo mismo ajena a la cuestión la mencionada empresa vial. Este es el punto central a considerar en este trabajo.

Sin perjuicio de lo anterior, pretendemos asimismo, ponderar otras circunstancias que pudieran dar lugar a la aplicación de dicha normativa, y que se encuentren originadas en la expectativa de seguridad en la prestación del servicio vial, tales como mal estado de los caminos, falta de señalización, circulación de vehículos en deficientes condiciones y que pudieran producir accidentes, entre otras.

A tal fin, intentaremos brindar una breve relación cronológica de los pronunciamientos en distintas instancias sobre la cuestión, sin perjuicio de lo cual, nos abocaremos en primer lugar a desentrañar algunas cuestiones conceptuales e históricas imprescindibles para dar marco al presente trabajo.

\section{ORIGEN Y FUNDAMENTO DE LAS CONCESIONES VIALES EN LA ARGENTINA}

La concesión vial se origina en nuestro país, bajo la regulación de la Ley $\mathrm{N}^{\circ} 17.520$, como una subespecie de la concesión de obra pública, por la que el Estado encarga a una o varias empresas privadas la construcción o el mantenimiento de una obra de gran envergadura -en este caso una ruta nacional-, concediéndole a cambio y como forma de pago la facultad de tarifar su uso a través de lo que se conoce como peaje, que cobra a los usuarios de la misma y cuya naturaleza jurídica, constitucionalidad, y limitación en el tiempo -ya que en algunos casos se han extendido sospechosamente en el tiempo-, han sido objeto de arduas discusiones.

El fundamento de mayor peso que surge del Proyecto de Ley, se traduce en la relación necesidad de infraestructura - escaso presupuesto, y la búsqueda de la inversión privada como mecanismo de financiamiento de las obras ${ }^{2}$.

\footnotetext{
${ }^{1}$ Artículo 1.124, Código Civil: "El propietario de un animal, doméstico o feroz, es responsable del daño que causare. La misma responsabilidad pesa sobre la persona a la cual se hubiere mandado el animal para servirse de él, salvo su recurso contra el propietario".

2 Así, se lee en los fundamentos del Proyecto de ley: “Esta ley tiende a crear en el país ese mecanismo económico financiero que permita aprovechar los esfuerzos de tantos distintos sectores que se encuentran postergados por nuestra falta de infraestructura, buscando en las fuentes de ahorro interno y externo el elemento insustituible para lograrlo y dando a la iniciativa privada el aliciente y los elementos para encauzar todos estos esfuerzos, alli en donde las condiciones de rentabilidad de las obras lo permitan".
} 
Las concesiones viales (fuertemente criticadas en su procedimiento de adjudicación) fueron parte del proceso de privatización y tercerización de la política neoliberal instaurada a partir de los años noventa, y contemplaron más del treinta por ciento del entramado de rutas nacionales pavimentadas, concentrando más de la mitad del tránsito y conectando las principales áreas urbanas y rurales del país, así como la mayor parte de los puertos y puentes internacionales.

Con la "privatización" concluyó, casi absolutamente, toda la actividad de prestación calificada como "de fomento", de caracteres no rentables o de escasa rentabilidad; a las empresas concesionarias sólo les preocupa "el negocio del servicio" y no la búsqueda de una vida mejor para los potenciales usuarios. De ahí que el tema debe ser expresamente contemplado en las reglamentaciones y volcarse en los contratos de concesión. (MOSSET ITURRASPE, 2004. p. 192).

Los pliegos licitatorios contenían la posibilidad de reajustes tarifarios basados en la variación del costo de vida de los países centrales ${ }^{3}$, y con largos plazos de amortización, que en realidad permitían seguir cobrando tarifas y obtener ganancias, a la postre exorbitantes, en comparación a las inversiones realizadas. La crisis de 2001, generó fuertes conflictos en este sector, iniciando una etapa de renegociación -prevista en el artículo $9^{4}$ de la misma norma legal-, que tuvo su punto de inflexión en el año 2003, cuando el Poder Ejecutivo decidió no prorrogar los contratos de concesión y llamar a nueva licitación a los fines de frenar las pretensiones de las empresas concesionarias, en particular, sobre la tarifación.

Tal cometido fue llevado acabo por el Órgano de Control de Concesiones Viales (OCCOVI). Sin embargo, podemos afirmar críticamente que los nuevos contratos aparecen desnaturalizados, ya que en la gran mayoría sólo apuntan al mantenimiento de las obras y no a la creación de nuevas, que fuera el fundamento originario del instituto de la concesión vial. En cuanto a las tarifas cada pliego licitatorio establece un cuadro tarifario e instrumenta la forma para la realización de sucesivos reajustes.

Este es el cuadro de situación a estos días, donde las rutas argentinas son noticia cada día como epicentro de accidentes debido al mal estado de las mismas, su obsolescencia en relación al volumen del transporte automotriz, la existencia de animales sueltos, etc. Y por otra parte, siguen siendo un gran negocio para las empresas concesionarias que se alzan con recaudaciones significativas en comparación con las inversiones en mantenimiento que realizan.

\footnotetext{
${ }^{3}$ En materia tarifaria se fijó, originalmente, un valor medio -en moneda local- de $\$ 1,50$ cada 100 kms., ajustable mensualmente según la evolución de un índice combinado de precios ( $\mathbf{4 0 \%}$ de la variación de los mayoristas, $30 \%$ de los minoristas y $30 \%$ de la variación del tipo de cambio del dólar estadounidense). Asimismo, se contempló la posibilidad de modificar las tarifas -previo acuerdo entre el Estado y los concesionarios- siempre y cuando se mantuviera inalterada la ecuación económico-financiera (es decir, la tasa de ganancia) de los concesionarios.

${ }^{4}$ Artículo 9 Ley 25.561: "Autorízase al Poder Ejecutivo Nacional a renegociar los contratos comprendidos en lo dispuesto en el Artículo $8^{\circ}$ de la presente ley. En el caso de los contratos que tengan por objeto la prestación de servicios públicos, deberán tomarse en consideración los siguientes criterios: 1) el impacto de las tarifas en la competitividad de la economía y en la distribución de los ingresos; 2) la calidad de los servicios y los planes de inversión, cuando ellos estuviesen previstos contractualmente; 3) el interés de los usuarios y la accesibilidad de los servicios; 4) la seguridad de los sistemas comprendidos; y 5) la rentabilidad de las empresas".
} 


\section{ACERCA DE LA NATURALEZAJURÍDICA DEL LLAMADO “PEAJE"}

Existen varias posturas que intentan desentrañar la verdadera naturaleza del canon o tarifa que constituye el llamado peaje, las que han sido adoptadas consecuentemente en diversos fallos como punto de inflexión para determinar si la relación entre empresa concesionaria y usuario existe realmente y si la misma es una relación de Derecho Público o de Derecho Privado.

La cuestión ha dividido profundamente a la doctrina autoral y judicial, no sólo respecto de la responsabilidad de tales accionados -Estado y concesionario-, sino también acerca de la naturaleza jurídica "del peaje": si es el precio o contraprestación en un acuerdo sobre la circulación libremente celebrado entre concesionario y particular, o bien se trata de una tasa que la empresa percibe por el servicio de mantenimiento de la ruta, como facultad delegada por el Estado (MOSSET ITURRASPE, 2004. p.p. 197-198).

Para quienes opinan que el peaje es un precio convencionalmente pactado entre particulares -tesis contractualista-, la solución al conflicto derivado de los daños ocasionados por animales sueltos se simplifica en una responsabilidad contractual a cargo de la empresa concesionaria por incumplimiento de los deberes derivados del convenio, o bien, en una relación de consumo, que permite asimismo la contemplación de una responsabilidad objetiva y solidaria.

Esta postura se basa en el hecho de que dentro de tal precio se incluye el Impuesto al Valor Agregado (IVA), y a partir de esta afirmación, se niega el carácter de impuesto o tasa que las empresas concesionarias perciben como atributo delegado por el Estado, ya que es sabido que no se pagan impuestos de impuestos.

Otra posición sostiene que si bien las partes quedan vinculadas entre sí por un contrato, el mismo reviste la forma de un contrato público -denominado contrato administrativo-, que vincula a la empresa concesionaria con el Estado, y a su vez, reglamenta las relaciones de la empresa con los usuarios. Este contrato es el resultado de una vinculación vertical entre particulares y el Estado, por la que el último se inviste de prerrogativas, ventajas o facultades exorbitantes de alteración, modificación o extinción del negocio en aras de lograr el bien común. Debido a ello, el derecho al cobro de peaje que se concede a las empresas concesionarias, no es más que una facultad delegada por el Estado para el cobro de una imposición destinada al mantenimiento de la obra pública.

\section{LOS ACCIDENTES CAUSADOS POR ANIMALES SUELTOS. EVOLUCIÓN DE LA JURISPRUDENCIA EN LA MATERIA}

Es bien sabido que la Argentina se ha caracterizado por ser un país de producción primaria, en el que el campo se constituye en protagonista. Es común observar en las rutas argentinas la presencia de animales (equinos y bovinos, entre otros), pastando a la vera del camino, sueltos o siendo arreados a sus lugares de pastura. Estas circunstancias han sido en numerosas ocasiones causantes 
de graves accidentes automovilísticos, que abrieron paso a sendos juicios de responsabilidad civil, y a partir de ellos, a la consideración de las distintas posiciones doctrinarias al respecto.

\subsection{La irresponsabilidad frente a la víctima. Teoría de la vinculación extracontractual}

Desde el año 2000, y en virtud de dos pronunciamientos de la Corte Suprema de Justicia de la Nación en las causas "Colavita, Salvador y otro c. Provincia de Bueños Aires" y "Bertinat, Pablo y otros c. Provincia de Buenos Aires y otro"s, el Alto Cuerpo parece haber cerrado la puerta a la aplicación de criterios jurisprudenciales que hicieran recaer en la empresa concesionaria la responsabilidad de estos casos.

La Corte, a través de fundamentos -aunque con una minoría disidente-, estableció lo que podría denominarse la teoría de la vinculación extracontractual o tributarista, sosteniendo que entre la empresa concesionaria y el Estado existe un contrato administrativo, en virtud del cual la primera actúa por delegación del segundo y sólo debe responder en el marco de un incumplimiento de deberes específicamente derivados de tal delegación frente a los usuarios, que a la postre, se constituyen en terceros ajenos a la relación administrativa.

Este razonamiento deriva en un ida y vuelta que libera de responsabilidades al Estado, por no tener intervención directa en la actividad (ya que media concesión), y al mismo tiempo a la concesionaria, porque si el concedente no responde, no puede delegar tal responsabilidad en la concesionaria. Se termina haciendo descargar la misma en el dueño o guardián del animal, que muchas veces y frente a la imposibilidad de acreditar la titularidad del animal, tampoco queda comprendido en la condena. Así lo sostuvo la Corte: "El ejercicio del poder de policía de seguridad que corresponde al Estado" -cuyo incumplimiento se le endilgaba"no resulta suficiente para atribuirle responsabilidad en un evento en el cual ninguno de sus órganos o dependencias tuvo parte, toda vez que no parece razonable pretender que su responsabilidad general en orden a la prevención de los delitos puede llegar a involucrarla a tal extremo en las consecuencias dañosas que ellos produzcan con motivo de hechos extraños a su intervención directa". Y agregó: "la omisión que se alega como sustento de la responsabilidad de la provincia no puede hacerla responsable de los daños causados por un animal del que no era propietaria ni guardadora" (Fallos 312:2138, consid. $5^{\circ}$ ).

Por otra parte se argumenta que, así como del contrato de concesión no surge la delegación del "poder de policía" en las concesionarias, y por ende las mismas carecen de imperium para actuar en el contralor de las adyacencias de los caminos, las mismas no deben responder.

Sostienen algunos autores que responde a la fundamentación administrativista: "Es el argumento de los administrativistas: falta la imposición expresa de este deber, sea en el contrato de concesión, en el "reglamento de explotación" o en otras normas aplicables" (MOSSET ITURRAS$\mathrm{PE}$, 2004. Nota al pie $\mathrm{N}^{\circ}$ 55. p. 199).

\footnotetext{
${ }^{5}$ Revista Jurídica La Ley, $2000-B$, p. 766 y ss.

${ }^{6}$ Revista Jurídica La Ley, $2000-B, p .376$ y ss.
} 
El poder de policía resulta indelegable, y en consecuencia, no puede hacerse cargar a la concesionaria por el accionar de terceros -dueños de animales que circulan por la ruta-.

Por otra parte, en ambos fallos se infiere la posibilidad de responsabilizar al Estado por incumplimiento u omisión de los deberes de contralor que surgen de la norma específica -del Código Rural de la Provincia de Buenos Aires, Ley 10.081-, relativos al control de mantenimiento de cercos o alambrados rurales.

Al respecto opina MARIENHOFF (1996), que en el Derecho Público no hay ningún texto que contemple expresamente la responsabilidad del Estado por las consecuencias de sus hechos o actos de omisión o de abstención, tal como existe en el ámbito del Código Civil, articulo 1074; que por vía de analogía puede inferirse su aplicación al terreno administrativista.

En el mismo sentido de unificar criterios sobre responsabilidad de particulares y el Estado, se pronuncian tanto doctrinarios del Derecho Público, como Privado.

"Así como ontológicamente no cabe diferenciar la responsabilidad contractual de la extracontractual, tampoco corresponde considerar diferencias estructurales entre la responsabilidad de los particulares o la del Estado" (GORDILLO, 2006. p. 3).

El derecho "vivo", el de nuestros tribunales, no adopta la misma actitud que los autores administrativistas: si bien admite la existencia de principios específicos, recurre en forma permanente al articulado del Código Civil (...) esta posición da muestras acabadas de que destruir la estructura no es eliminar todos sus brotes. Es que el derecho no puede dividirse en compartimentos estancos, y, mucho menos en materia de responsabilidad (KEMELMAJER DE CARLUCCI, 1985. p. 211).

En igual sentido se expresa LE TORNEAU (2004, p. 22), considerar que "Cosa muy distinta es la responsabilidad administrativa, es decir, la obligación que incumbe a una persona "moral" de derecho público de reparar el daño que ella ha causado. Esta responsabilidad posee reglas específicas, pero una unidad de inspiración la pliega a la responsabilidad civil, de la cual utiliza ciertas nociones".

Ahora bien, concluye la Corte en "Colavita" que, para el caso de demandar al Estado por la circunstancia omisiva, la responsabilidad que recaería sobre él tendría carácter subjetivo, y pondría en cabeza del actor la necesidad de acreditar fehacientemente la omisión de tal control. Sin perjuicio de ello, y al faltar en las causas en análisis la acreditación de tales extremos, el Estado Provincial, quedó exonerado.

En la causa "Bertinat" vuelve sobre estos considerandos, pero distinguiendo entre rutas rurales y urbanas, y estableciendo una suerte de presunción de la omisión en el control de la presencia de animales sueltos, derivada de la frecuencia de accidentes causados. En relación a las concesionarias, el planteo de irresponsabilidad sigue siendo el mismo.

En conclusión, de acuerdo con estos fallos, para lograr una reparación de los daños producidos por un accidente causado por animales sueltos en una ruta concesionada, el damnificado deberá dirigir su acción contra el Estado (por incumplimiento de los deberes del funcionario público, artículo 1.112, Código Civil), acreditando los extremos de la omisión o falta 
de control, y concurrentemente contra el dueño o guardián del animal causante del accidente (artículos 1.113 y 1.124, Código Civil), cuando pudiera individualizarlo.

Cabe destacar, que en pronunciamientos sucesivos, y en causas arribadas a través de Recurso Extraordinario, directamente se revocan todos los pronunciamientos de tribunales inferiores que contradigan esta doctrina, sin entrar a analizar si las sentencias recurridas son arbitrarias o carecen de fundamentación, lo que resulta criticable porque deja de lado el verdadero objeto de dicho recurso judicial. Este es quizás el punto más crítico del pronunciamiento, porque rompe la estructura de la faz recursiva y cierra la vía a la revisión judicial y las garantías de un debido proceso.

\subsection{Teoría de la vinculación obligacional}

PIZARRO (2006), en un detallado trabajo de análisis de un fallo de la Corte, describe esta postura como la desplegada por el Tribunal Superior de Justicia de la Provincia de Córdoba, en autos "Hernández, Emilio c. Red Vial Centro S.A."(LLC, 2001-1077 y ss.).

De acuerdo a este criterio, existe una relación antecedente entre Estado y concesionaria -contrato de Derecho Público-, que coloca al usuario en una situación jurídica obligacional única e inescindible en relación a la empresa concesionaria: es un tercero respecto de esa relación antecedente, pero queda en cierto modo y para ciertos efectos vinculado a la misma. En orden a ello, puede demandar a esta última fundándose en una responsabilidad contractual -cuando el daño derive del incumplimiento de algún deber impuesto en el contrato administrativo-, o extracontractual -cuando derive de un acto ilícito, de acuerdo al artículo 1.107, Código Civil-, según el caso. De ello deriva que resulta absolutamente innecesario determinar si el peaje es un precio o un impuesto.

Ahora bien, este Tribunal considera que la responsabilidad pesa en forma directa en el dueño o guardián del animal, que puede concurrir con la de la empresa; pero en relación al incumplimiento del deber de seguridad que pende sobre la concesionaria de mantener sin obstáculos la vía, lo considera una obligación de medios, introduciendo la inversión de la carga probatoria sobre el usuario, que, en cada caso para responsabilizar a la empresa, deberá acreditar la omisión en el cumplimiento de dicho deber.

\subsection{Teoría de la vinculación Contractual. Responsabilidad de la empresa concesionaria}

Sin embargo, a partir del año 2006, más exactamente, a partir del pronunciamiento de la Corte en el caso "Ferreyra, Victor D.y otro c. V.I.C.O.V.S.A."(C.S.J.N., 2006-03-21), comienza a modificarse el criterio de la hasta ahora mayoría, especialmente a través de los votos de los Dres. Lorenzetti y Zaffaroni, que introducen el fundamento de la responsabilidad contractual sobre las concesionarias, y más específicamente, la consideración de la relación usuarioempresa prestataria del servicio como una relación de consumo.

Asimismo, en fallo posterior, "Bianchi, Isabel del Carmen c. Provincia de Buenos Aires y Caminos del Atlántico Sur"(CSJN, 2006-11-07) y, sin perjuicio de explicar que no podía aplicarse la ley 24.240 -debido a la fecha en que había ocurrido el accidente-, la Corte manifestó 
que no cabía duda de que el vínculo era contractual ya que el usuario pagaba un precio o canon para el uso de la ruta y servicios consiguientes.

Expresó en esta oportunidad el Tribunal que, al existir una relación contractual, cabe sostener que el concesionario no asume una obligación de dar el uso y goce de una cosa, sino de prestar un servicio. Esta calificación importa que haya una obligación nuclear del contrato, constituida por la prestación encaminada al mantenimiento de la ruta en todos sus aspectos y, también, deberes colaterales con fundamento en la buena fe -art. 1.198, Código Civil-. Entre estos últimos existe un deber de seguridad de origen legal, e integrado en la relación contractual, que obliga al prestador a la adopción de medidas de prevención adecuadas a los concretos riesgos existentes en la ruta concesionada, en tanto resulten previsibles.

Esta nueva visión de la cuestión caracteriza entonces a la responsabilidad de la empresa como objetiva, derivada de una obligación de resultado, que es la de prestar el servicio de manera segura e idónea.

Se agrega a esta fundamentación el concluyente voto del Dr. Lorenzetti, que sobre el particular opina: "La relación contractual de derecho privado entre el concesionario y el usuario hace nacer una obligación de seguridad de resultado, alcanzada por parámetros objetivos de atribución, a cargo de aquélla, pues se trata de prestar un servicio de carácter continuado, moralmente reflejado por el ingreso a las rutas en forma masiva, y de uso simultáneo, sin que pueda existir una deliberación previa de forma que permita al usuario modificar las condiciones de la prestación".

Esto es, se allana el camino al usuario, que ahora le basta solamente con probar la existencia del hecho y el daño padecido, recayendo sobre la empresa la prueba de una causa ajena para su liberación. Sin embargo, en relación a la prueba del caso fortuito o la fuerza mayor -entendidos ambos como acontecimientos imprevisibles e inevitables- la sentencia cierra la puerta a la acreditación de tales extremos como causa de exoneración, ya que de uno de los considerandos se desprende que la existencia de animales sueltos en ruta (por su condición de hecho común, particularmente en rutas rurales) no puede entenderse como algo extraordinario e imprevisible para la empresa.

Por otra parte, y aplicando los principios de ponderación de la responsabilidad del Análisis Económico del Derecho, podría afirmarse en estos extremos, que es el prestador del servicio quien está en mejor posición para hacerse con menores costos de la información sobre la circulación de los animales y sus riesgos, y, por el contrario, el usuario es quien está en una posición desventajosa para obtener esos datos, lo que sólo podría hacer a un altísimo costo.

Por último, la responsabilidad del concesionario puede concurrir con la del dueño o guardián del animal, y agregamos, con la propia del Estado -ambas indiscutiblemente de carácter extracontractual-, $y$ puede ser distribuida por el primero a través de la mejor prevención de accidentes o la contratación de un seguro adecuado. 


\subsection{La relación de consumo}

Tal como lo apuntáramos al comienzo, en "Ferreyra" -decisorio que se constituye en un verdadero leading case-, se profundiza en la noción del contrato calificándolo como un "contrato de consumo", introduciendo como marco regulatorio de la relación -además de las normas que traducen los principios generales en la materia-, aquellas específicas de defensa del consumidor (artículo 42 de la Constitución Nacional, Ley 24.240 y complementarias).

He aquí el punto de inflexión de este trabajo, ya que por vía de interpretación se produce la inclusión de este especial servicio público derivado de la concesión de redes viales como una relación de consumo, que prima facie, no resulta expresamente incluido en la regulación de la Ley 24.240 (artículo 25 y ss.), ni aún después de la última reforma introducida por Ley 26.361 (del año 2008).

Igualmente importante, resulta la incorporación de la noción de servicio defectuosamente prestado, derivado de una omisión de deberes esenciales reconocidos por la normativa tuitiva, en particular, la obligación de prestarlo en condiciones razonables de seguridad para el usuario.

La responsabilidad de la concesionaria se desprende entonces del incumplimiento del deber que pesa sobre la misma, de brindar un servicio seguro y confiable a los usuarios de la ruta, lo que lo torna defectuoso.

"El ciudadano común que accede a una ruta concesionada tiene la confianza fundada en que el organizador se ha ocupado razonablemente de su seguridad" (Del voto del Dr. Lorenzetti, considerando 27).

"La mayor dificultad para emplazar la relación de consumo estriba en que el servicio (al que se refiere el artículo 40 de la Ley 24.999), no proviene de la acción activa del servicio sino de la omisión de cuidado, ello no excluye que recaiga en el concesionario un deber jurídico de remover los obstáculos -incluidos los animales sueltos- en atención a que la facultad de actuar, cuando genera riesgos para los usuarios, se trasmuta en una carga de acción para evitar el daño"(GALDOS, 2000, p. 494).

El derecho a la seguridad debe ser entendido en su exacta dimensión: como un derecho fundamental operativo con consagración constitucional, que "implica una decisión valorativa que obliga a la sociedad toda a desempeñar conductas encaminadas al cuidado de lo mas valioso que existe en ella: la vida y la salud de los habitantes, ricos o pobres, poderosos o débiles, ancianos o jóvenes, expertos o profanos" (LORENZETTI, 2009, p. 48).

En lo que respecta a la existencia de una omisión, bien sabemos que no toda falta en el obrar genera responsabilidad, sino que la misma debe estar expresamente prohibida en la norma o implícitamente determinada por la violación al deber general de evitar dañar a los demás, tal surge de la interpretación mayoritaria que la doctrina hace del artículo 1.074 del Código Civil, y que fuera objeto de análisis ut supra.

Así en relación a esta inquietud que plantean algunos autores respecto de la actividad desplegada por la empresa, que omite realizar lo necesario para evitar la presencia de animales sueltos, traemos a colación lo que el jurista TRIGO REPRESAS (2006, p. 1; 2007, p.p. 7-8) ha 
expresado al respecto: "La omisión encierra un concepto normativo, porque sólo tiene sentido cuando la inactividad del individuo se considera con referencia a una norma que imponía una determinada actividad; ya que si así no fuese, no habría posibilidad práctica de establecer la existencia de la omisión, puesto que el hombre no deja de actuar mientras vive, al punto que incluso el permanecer en reposo puede ser calificado como una actividad (dormir, estar sentado, etc.)"

En esta circunstancia, se impone a la empresa un obrar tendiente a la prestación del servicio de carretera en forma segura e inocua para el usuario -según se desprende de la normativa de defensa del consumidor y usuario, arts. $5^{7}$ y $6^{8}-$, y la falta de los debidos controles para evitar la presencia de animales se constituye en una omisión a ese obrar, que genera la presunción de su responsabilidad frente al accidente ocurrido, poniendo en su cabeza el imperativo de acreditar una causa ajena para liberarse de la obligación de indemnizar.

Por otra parte, al sentar el criterio de considerar la existencia de una relación de consumo como basamento para la imputación de responsabilidad a la concesionaria, se abre sustancialmente el campo de atribución de la misma al ámbito precontractual -por incumplimiento de los deberes de información, art. 4, Ley 24.2409-, y se deja de lado la necesidad de determinar la existencia de una verdadera relación contractual previa entre los sujetos, en virtud de que la propia norma tuitiva no establece distinciones de grado sino un sistema de responsabilidad único y especial, representado por el carácter objetivo de la misma y la solidaridad de los proveedores.

En el año 2007, un nuevo decisorio convoca al análisis de la cuestión, también motivado por vía de Recurso Extraordinario contra una sentencia -al igual que en el caso “Ferreyra”-, del Superior Tribunal de la Provincia del $\mathrm{Chaco}^{10}$. En esta causa el Máximo Tribunal vuelve a aplicar su posición fundada en el reconocimiento constitucional del Derecho del Consumidor, y haciendo recaer la responsabilidad de la concesionaria del servicio vial en un vínculo conformado por la relación de consumo-concepto incorporado al art. 3 de la Ley $24.240^{11}$, por Ley $26.361-$, que

\footnotetext{
${ }^{7}$ Art. 5, Ley 24.240: "Protección al Consumidor. Las cosas y servicios deben ser suministrados o prestados en forma tal que, utilizados en condiciones previsibles o normales de uso, no presenten peligro alguno para la salud o integridad física de los consumidores o usuarios".

${ }^{8}$ Art. 6, Ley 24.240: "Cosas y Servicios Riesgosos. Las cosas y servicios, incluidos los servicios públicos domiciliarios, cuya utilización pueda suponer un riesgo para la salud o la integridad fisica de los consumidores o usuarios, deben comercializarse observando los mecanismos, instrucciones y normas establecidas o razonables para garantizar la seguridad de los mismos (...)".

${ }^{9}$ Art. 4, Ley 24.240: “Información. El proveedor está obligado a suministrar al consumidor en forma cierta, clara y detallada todo lo relacionado con las características esenciales de los bienes y servicios que provee, y las condiciones de su comercialización. La información debe ser siempre gratuita para el consumidor y proporcionada con claridad necesaria que permita su comprensión". (Artículo sustituido por art. $4^{\circ}$ de la Ley N²6.361 B.O. 7/4/2008).

${ }^{10}$ C. S.J.N.: "González Torres M. c. Deluca J.A. y/o Servicios Viales S.A. s/Indemnización de daños y perjuicios y daño moral".

11 Art. 3, Ley 24.240: "Relación de consumo. Integración normativa. Preeminencia. Relación de consumo es el vínculo jurídico entre el proveedor y el consumidor o usuario. Las disposiciones de esta ley se integran con las normas generales $y$ especiales aplicables a las relaciones de consumo, en particular la Ley № 25.156 de Defensa de la Competencia y la Ley № 22.802 de Lealtad Comercial o las que en el futuro las reemplacen. En caso de duda sobre la interpretación de los principios que establece esta ley prevalecerá la más favorable al consumidor. Las relaciones de consumo se rigen por el régimen establecido en esta ley y sus reglamentaciones sin perjuicio de que el proveedor, por la actividad que desarrolle, esté alcanzado asimismo por otra normativa específica". (Artículo sustituido por art. $3^{\circ}$ de la Ley $N^{\circ} 26.361$ B.O. 7/4/2008).
} 
origina un deber de seguridad a cargo de la misma como obligación de resultado, quedando vinculada a la responsabilidad derivada del mismo hasta tanto no se destruya el nexo causal.

Actualmente, podemos igualmente encontrar fallos de instancias inferiores que siguen aplicando el criterio de "Colavita" (véase sentencia de la CNCiv., sala G en autos: "Hernández, Oscar Alberto y otro c/ Nuevas Rutas S.A. s/ daños y perjuicios”, 2007-06-27), motivados quizás en el hecho de que la Corte podrá entenderlos -si llegan por vía recursiva- analizando la razonabilidad de la decisión y no el apartamiento de su actual doctrina, como lo había hecho a partir del primer pronunciamiento.

Sin perjuicio de ello, la mayoría de los tribunales han venido a adherir -algunos fundados en motivos de economía procesal- al criterio de la CSJN, en "Ferreyra". A manera de ejemplo citamos el caso de la Suprema Corte de Justicia de la Provincia de Buenos Aires, que a partir de "Castro, Luis y otra v. Camino del Atlántico S.A.s/daños y perjuicios", sentencia del 22 de diciembre de 2008, ajusta su opinión a los fundamentos esbozados por el Máximo Tribunal.

\section{CONCLUSIONES}

Baste para concluir que se ha recibido con beneplácito esta modificación en el criterio de interpretación del Alto Cuerpo Judicial, que a la postre, se conforma en un verdadero cambio paradigmático respecto de las reglas y normas de responsabilidad aplicables al caso, y ha venido traduciendo una posición que hoy cuenta con mayor basamento legal, a partir de la incorporación al texto de la Ley 24.240 del concepto de relación de consumo, y la ampliación de la noción del consumidor, con la figura del bystander. Asimismo, muestra coincidencias con la tesis más actual de pretender una teoría general de las relaciones jurídicas de servicio con base en las normas del Derecho de Consumo, caracterizadas por la relativización de los efectos inter partes y la superación de la summa divisio entre obligaciones contractuales y extracontractuales, tal como lo pone de resalto LIMA MARQUES (2005).

Por otra parte, el hecho de considerar que los tribunales en general, han sido -desde la sanción de la Ley de Defensa del Consumidor en 1993-, bastante remisos a su aplicación, pone de resalto que la Corte Suprema se haya expedido caracterizando, además, una situación que prima facie no encuadra dentro de sus prescripciones -ya que la norma regula expresamente sólo a los servicios públicos domiciliarios-, resulta elogiable como precedente, a más que establece a rajatabla la responsabilidad del ente concesionario dejando abierta la puerta para responsabilizar solidariamente al propio Estado.

Frente a este nuevo panorama, se vislumbra la efectiva aplicación por vía extensiva o analógica a otros supuestos derivados del carácter contractual del vínculo usuario-concesionaria del servicio vial, con fundamento en un factor de imputación objetivo: tales la existencia de obstáculos (véase fallos: "Malcervelli Horacio F. y otros c/ Grupo Concesionario del Oeste SA s/ daños y perjuicios". "Conti, Ma. Elvira c/Autopistas del Sol S. A. y otro s/ Daños y Perj." - Cam. Nac. Apelac. Civil - Sala G - 7/11/07), el mal estado de los caminos y su falta de seña- 
lización, la presencia de automóviles que no tengan las condiciones de seguridad mínimas requeridas, y aún de conductores alcoholizados.

Ahora bien, a fuerza de ser justos es dable ser críticos y abocarse a analizar estos nuevos paradigmas que propugnan una responsabilidad fundada en un deber de seguridad -como obligación de resultado de la que nace responsabilidad objetiva-, que aparece en el voto de los jueces de la Corte con suficiente amplitud, y que, al decir de autores como PIZARRO (2006), requieren de un estudio más profundizado para la determinación de la naturaleza y alcance de dicho vínculo, a los fines de una adecuada delimitación.

Desde otra perspectiva, habrá que dilucidar si este empeño en responsabilizar a las empresas concesionarias de manera tan estricta, no llevará a nuevas formas de injusticia, y con ella a renovadas discusiones acerca de la distribución de los costos de la actividad, o la posibilidad de aplicación del instituto del daño punitivo, regulado en el art. 40 bis, de la Ley 24.240, con las derivaciones que apareja.

Igualmente trascendente a la hora de intentar predecir las reales consecuencias de estas decisiones jurisprudenciales, se rescata la opinión de LÓPEZ DEL CARRIL (2006), cuando afirma que las concesiones están hechas para durar limitadamente en el tiempo, en tanto que los juicios de responsabilidad civil pueden tramitarse durante muchos años, echando por tierra las justas pretensiones de las víctimas por posibles liquidaciones de las empresas en el ínterin.

Más allá de estas viscitudes, creemos que estamos en el buen camino, y que la condena a las empresas concesionarias propende a un mejor cumplimiento de uno de los principios rectores de la responsabilidad, cual es, el incentivo a la prevención de daños.

Frente a la imposición de una responsabilidad objetiva, las empresas se verán en la necesidad de articular mecanismos más eficientes para prevenir los accidentes derivados de la existencia de animales sueltos, o bien, a distribuir los riesgos a través del un seguro.

Lo cierto es que la defensa del consumidor y del usuario ha comenzado a tener la trascendencia que merece, $\mathrm{y}$ a no ser visto como un mero subsistema de derechos, sino como un haz de principios rectores que traspasan cada vez más el extenso marco del Derecho Privado Patrimonial, a la manera de un verdadero "diálogo de las fuentes" al decir de los iusprivatistas más destacados (SOZZO, 2009).

ROSENAU (cita de LORENZETTI; LIMA MARQUES, 2005, p.p. 132-133), al retratar la crisis de la ciencia actual, sostiene que los posmodernos se pueden clasificar en escépticos o afirmativos. Nos consideramos comprendidos en el segundo grupo, de "aquéllos que resaltan el diálogo de las fuentes, constatan la existencia de nuevos paradigmas y verdades, verdades que, igualmente más tolerantes, fluidas, menos universales y ahora microsistémicas, pueblan de sentido el ordenamiento actual", y lo revitalizan en aras de una mayor justicia. 


\section{REFERENCIAS BIBLIOGRÁFICAS}

GALDOS, J. (2000) Peajes y animales sueltos ¿Clausura de un debate?. Revista Jurídica La Ley. Ed. La Ley, Buenos Aires. 2000 -E. p.p. 494 y ss.

GORDILLO, A. (n.d.) Tratado de Derecho Administrativo. Tomo II. Fundación Derecho Administrativo. Consultado el 20 de abril de 2011 en: www.gordillo.com

KEMELMAJER DE CARLUCCI, A. (1985) Responsabilidad del Estado (Una búsqueda de principios comunes para una teoría general de la responsabilidad), en Estudios en Homenaje al Dr. Guillermo Borda. Ed. La Ley, Buenos Aires.

LE TORNEAU, P. (2004) La Responsabilidad Civil. Trad. Javier Tamayo Jaramillo. $\mathbf{1}^{\text {a }}$ ed. Ed. Legis, Bogotá.

LORENZETTI, R. L. (2009) Consumidores. $\mathbf{2}^{\mathrm{a}}$ ed. actualizada. Ed. Rubinzal Culzoni, Santa Fe.

LORENZETTI, R.; LIMA MARQUES, C. (2005) Propuesta de una teoría general de los servicios con base en el Código de Defensa del Consumidor. La evaluación de las obligaciones vinculadas a los servicios remunerados directa o indirectamente en Contratos de servicios a los consumidores. Ed. Rubinzal Culzoni, Santa Fe. p.p. 131-191.

LOPEZ DEL CARRIL, G. (2006) El fallo "Ferreyra": cla clausura de un debate? en $R \boldsymbol{e}$ vista de Responsabilidad Civil y Seguros. Año VIII. N VI.Ed. La Ley, BuenosAires. p.56 y ss.

MARIENHOFF, M. (1996) Responsabilidad extracontractual del Estado por las consecuencias de su actitud omisiva en el ámbito del derecho público. Ed. Abeledo Perrot, Buenos Aires. p. p. 18-24.

MOSSET ITURRASPE, J. (2004) (Dir.) Responsabilidad por Daños. Responsabilidad del Estado. Tomo X. Ed. Rubinzal Culzoni, Santa Fe. p.p. 192 y ss.

PIZARRO, R. D. (2006) Responsabilidad de las empresas concesionarias de peaje en un reciente fallo de la Corte Suprema en Revista de Responsabilidad Civil y Seguros. Año VIII. No III. Ed. La Ley, Buenos Aires. pp. 36-38. 
SOZZO, G. (2009) El estado actual de la problemática de los riesgos derivados del consumo (dimensiones reparatoria, preventiva y precautoria) en Revista de Derecho Privado y Comunitario 2009-1. Consumidores. $1^{\mathrm{a}}$ ed. Ed. Rubinzal Culzoni, Santa Fe. p.p. 367-401.

TRIGO REPRESAS, F. (2007) Omisión que viola el deber legal de obrar impuesto formalmente en Revista de Derecho de Daños. La omisión en el Derecho de Daños. Ed. Rubinzal Culzoni, Buenos Aires. p.p. 7-8.

TRIGO REPRESAS, F. (2006) Hecho ilícito por omisión en Revista de Responsabilidad Civil y Seguros. Año VIII. Nº III. Ed. La Ley, Buenos Aires.

\section{CURRÍCULUM VTTAE VERONICA MARIA LAURA GLIBOTA LANDRIEL}

Abogada. Candidata a doctora en Derecho por la Facultad de Derecho y Ciencias Sociales y politicas de la UNNE (tesis doctoral en estado de evaluacion).

Profesora adjunta regular de Instituciones de Derecho Privado II, docente regular de instituciones de Derecho Privado I, de la Facultad de Ciencias Económicas de la UNNE.

Miembro del Instituto Nordeste de la Academia Nacional de Derecho de Córdoba. Investigadora categorizada.

Miembro de equipo de investigacion con proyecto acreditado.

\section{vglibota@eco.unne.edu.ar}

